\title{
Using the Extra Curricula Scientific Activities Based on The Multiple Intelligences Theory in Developing the Environmental Awareness the Primary Pupils Have
}

\author{
Hala Ezz EIDeen Mohammed, Soad Mohammed Magraby and Eman Mohammed Amin Al- \\ Kady
}

Faculty of Education, South Valley University

\begin{abstract}
Based on the Self Observation \& the Previous Studies' Results \& the Study of the Actual Reality of education in Egypt, it had been Appeared that there is a Shortage of the Environmental Awareness that fits the primary stage pupils, so this Study tried to Recognize the Effect of the use of Extracurricular Scientific activities Based on the Multiple Intelligences theory in the Development of Environmental Awareness that fits the primary stage pupils. To Achieve such Aim, the Next Procedures had been Done: Determine the Dimensions of Environmental Awareness, and types of Extracurricular Scientific activities, Prepare the Tools of the Study (Environmental Awareness Scale), Make the Experimental Survey and it had been Following the Experimental Approach (Design of Equal Groups, Design of Control Group With Pre-Post Measuring), as Study Tool had been Applied on the Group of the Study Before the Use of Extracurricular Scientific Activities Based on the Multiple Intelligences theory, and Use these Activities on them ,Applying the Study Tool on the Group of the Study Another Time After the Use of the Activities. The Results of this Study Refers to the Effectiveness of the Use the Extracurricular Scientific Activities Based on the Theory of Multiple Intelligences in the Development of Environmental Awareness that fits the primary stage pupils. Therefore, there is a need to prepare a program in the Islamic culture based on self-regulated learning for developing some religious concepts and tourism attitudes of the students in the first stage of Faculty of Tourism and Hotels.
\end{abstract}

Keywords: The Extracurricular Scientific; Activities; Multiple Intelligences; Environmental Awareness

Citation: Mohammed et.al., prepare a program in the Islamic culture based on self-regulated learning for Developing some religious concepts and tourism attitudes of Faculty of Tourism and Hotels Students. SVU-Journal of abstract 2019, Vol.1: pp2 (retrieved from the Journal of Educational Sciences; 2018, No.34; pp35).

Copyright: Publisher South Valley University. This is an open access article distributed under the terms of the creative common attribution license, which permits unrestricted use, distribution and reproduction in any medium provided the original author and source are created. 